\title{
UN/FAIR REFERENCES
}

Keywords

Copyrights

Copies

Originality

Law

Exhibition
We usually understand the discipline as a collection of previous examples that can be used and manipulated as references for the design process.

However, have we ever asked ourselves to what extent are we contravening the copyrights owned by previous colleagues? Are we aware of these regulations? This interview not only clarifies the history of copyright in architecture, but also seeks for the opportunities and possibilities underlying those legal concepts.

ne of the most copied recipes in culinary history is the 'molten chocolate cake,' a warm dessert that has a moist chocolate sponge surface and a runny and saucy cocoa heart inside. The recipe, launched in 1981, was the outcome of a two-year experiment by the French chef Michel Bras, who aimed at developing a very sophisticated technique that allowed this effect. Its rapid spread throughout kitchens around the world was followed by a debate on potential copyright claims. It was quickly understood that granting patents to kitchen recipes was not really 'a piece of cake,' since a patentable invention can neither have existed before, nor be an obvious improvement or alteration of a previously known invention. In addition, the formula's slight variations and alterations, even by the author himself, made it impossible to establish an unchanging original to be copied.

Paradoxically, a cookbook is protected by international copyright regulations. Once substituted the exclusive French bakery delight 
ANA MILJAČKI

Associate Professor of Architecture, Massachusetts

Institute of Technology, Cambridge, MA, USA

Entrevista y texto de / Interview and text by

FABRIZIO GALLANTI

Professor, McGill University, Montreal, Canada for a building or an architectural design, it is easy to fall into an analogous condition of ambiguity and legal vacuum. The transition between an idea, its representation through drawings and models, and its physical execution, belongs to the field of technical tasks rather than to the work of an author. In addition, the history of Western architecture has been based on imitation, replication, adaptation of examples and models - in some cases the literal adaptation of entire buildings - although in most circumstances imitation is reduced to fragments, constructive techniques or details. Only recently, copyright legislation - originally developed for literature - is expanding its notions to include physical and concrete elements within the architectural work (until then, only drawings enjoyed this kind of protection). However, lawsuits remain only a few when compared to other practices, given perhaps the difficulty of using measuring tools that are accurate enough to reassure the criteria of a judge before ruling a verdict: while there are digital programs that can undoubtedly demonstrate how a few seconds of music belong to a different composition, it is not easy to demonstrate that a kind of rough cast concrete has been literally copied from Tadao Ando. Furthermore, it is difficult for Tadao Ando to bring the copier to justice.

Within this fascinating field, where legal and architectural issues on invention are overlapped, is where the question of models and copies is restored through a series of inquiries carried out in recent years by MIT architect and professor Ana Miljački and designer Sarah Hirschman. In this interview, Miljački reveals the reasons for this research project and its current developments. 


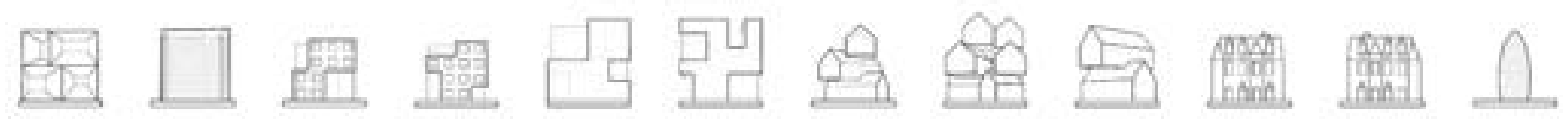

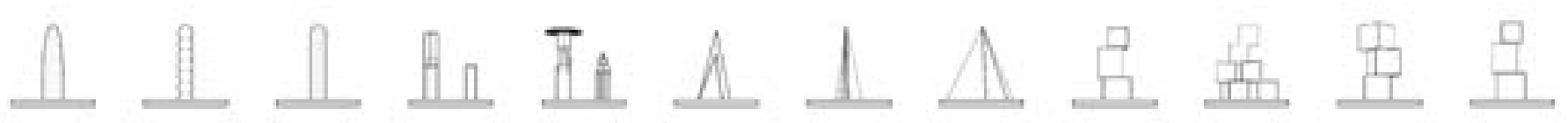

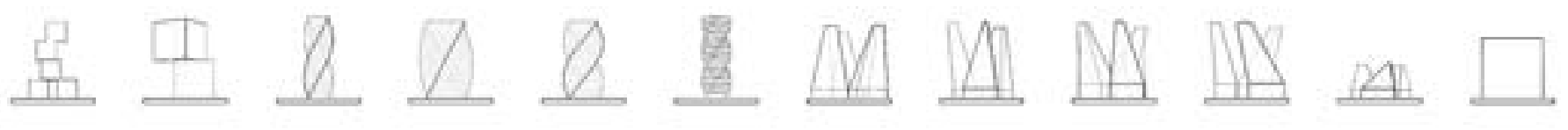

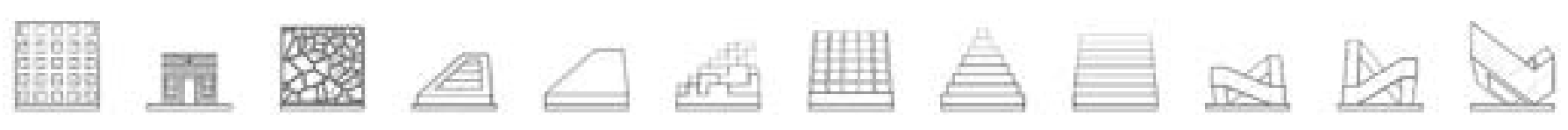

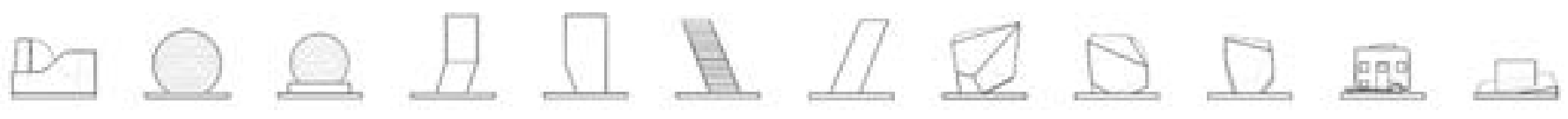

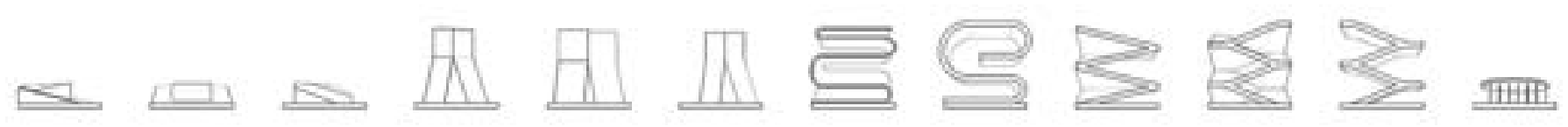

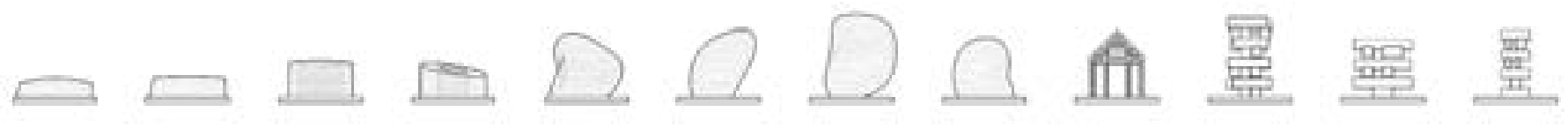

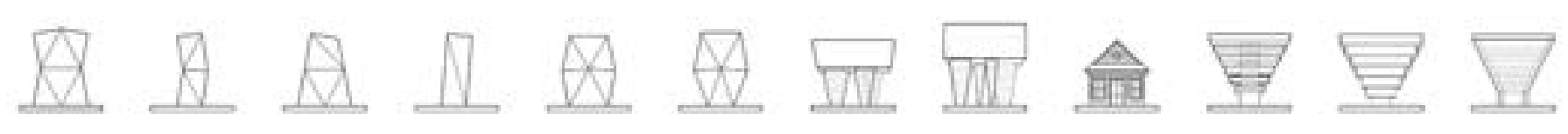

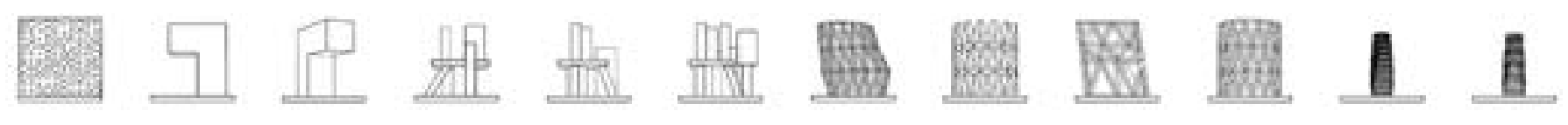

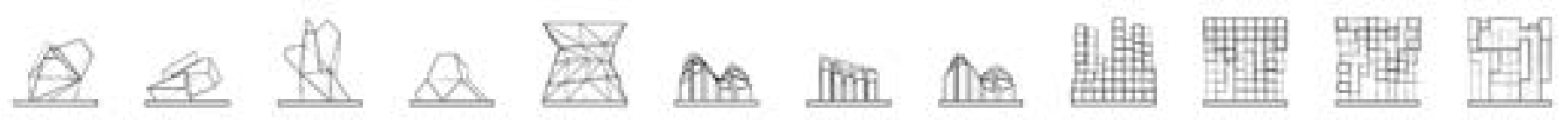

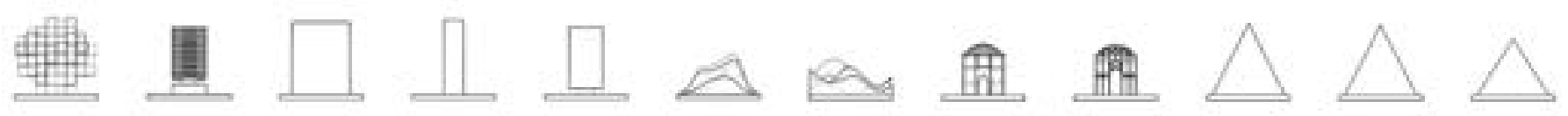

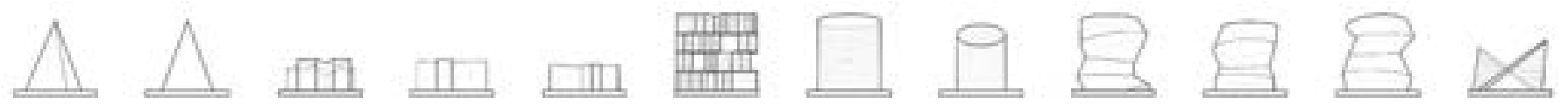


FABRIZIO GALLANTI: Why (and when) did you start to be interested in the issue of copyright in architecture?

ANA MILJAČKI: You know how you begin to become aware, slowly, as you walk the city, scroll through your feed, flip magazines, that the trends - some bigger set of protocols whose mechanics are not immediately obvious - have begun to rewrite your desires. As a critic and a teacher I am similarly sensitive to the mood changes and the temperature in the design studio within the university: the books that sit on students' desks, the tools that are being used, the topics that seem to produce sparks. My students keep me in the now. Over the last 8 years or a decade, in parallel with the emergence of Facebook, Instagram, blog-format Internet journals and platforms, a whole new set of habits involving accessing architectural information has developed. It seemed important to me, again thinking as a pedagogue, to find a way to problematize the ease with which architectural ideas seemed to travel, to enter some friction into the mix, not because travel or ideas themselves were problematic, but because ideas were getting flattened too quickly as well. The high-speed Internet and our habits of use, have allowed indeed an instantaneous access to an unprecedented number of architectural images. High quality works exist on the same platform as fairly random images, all equally flattened and low-res, and we all copy, translate, transform, approximate those images objectively more than when we did not see them. It is natural that litigious mechanisms would follow this proliferation of images and their reproduction. And in a sense architecture is a latecomer to the courtroom; protection has existed for over a century for architectural drawings, but just as drawings.

FG: Copyright emerged within literature (Victor Hugo was its main advocate): how has it been adapted to suit architecture?

AM: Architecture and architectural images were not disseminated as fast, nor did they have the same relationship to the market as books. No architect has ever been as adamant about the need for copyright protection as Victor Hugo was and the legislature has been slow in codifying the work of architecture. In what medium does it reside? Drawing, 3D model, building, or images flickering on screens? And if the building itself were to embody the intellectual work 
(which we hope it does, no?), what exactly gets to be protected? The idea? Or its representation and embodiment? Is a building useful, and if so should anyone have monopoly of use over the ideas that conjured it up? Should it be the best idea or the intellectual labor as such which gets protected from being copied by others? It is messy.

In 1989, after stalling for more than a century on it, the U.s. accepted the most comprehensive international legislature governing copyright, the Berne Convention. The Berne Convention was first signed in 1886 by ten countries, and now includes 171 member countries. It made mention of architecture early, though without much clarity on how to apply the law to these works, unless they were twodimensional drawings meant for construction. A year after the U.S. accepted the Berne Convention, the Architectural Works Copyright Protection Act [AWCPA] was passed with a much more specific set of rules now applying to architectural ideas in many different media (past and future), but also including a stipulation that useful aspects of an architectural project could not be copyrighted while architectural expressions of 'myths and ritual' as Michael Graves had put it, could, as long as one could draw the line between these. If the two were fused the project is not copyrightable.

FG: The intellectual model upon which Western architecture has been based for centuries revolves around notions of models, archetypes, typologies and copies. How do you see a balance between such lineage and the quest for originality and novelty?

AM: I agree with your first statement here. Our discipline does exist as such even if we don't see it in terms of its history, and the history of its internal debates on authorship, and that is why I am entirely on the left side of the copyright law. I think the discipline does not benefit from the legal definition of originality. And yet, some of the ways that the law describes 'fair use' are perhaps the clearest way to talk about balancing originality with the disciplinary archive. 'Fair use' doctrine allows for commentary, parody, in a sense transformative use of previous work to be understood as original.

FG: In your research, you identify a potent external factor, laws and regulations, in the definition of architecture. What is your assessment of such condition?

AM: When we think alongside law, the conceptual separability that I mentioned above (between utility and expression) it very quickly ends in literal separation of use and expression, with form splintering somehow unevenly between the two. 
As a teacher, I find this horrifying, but the horror perhaps comes from the specifically architectural, prospective view. It is perhaps a vocational hazard, to want to see the law as generative. Indeed, if we were to teach our students that they could ensure maximum copyright protection for their projects, the architectural outcome of that thinking would be unlike most things we know. The law is explicitly not generative, it is protective, it is called upon only once the claim of infringement is made, not before it. So we are safe in a certain sense. But I also believe that it is our collective awareness of our indebtedness to the disciplinary knowledge that safeguards architecture from endless litigation.

FG: Laws regulating architectural copyright were issued in the U.s. in 1990, what has been the trajectory so far and which have been the salient moments? I noticed that you developed a timeline.

AM: Well, apart from the passing of AWCPA, there have been no watershed cases to clarify the law in one big sweep, but instead small, incremental clarifications of the way substantial similarity might be determined and what its repercussions ought to be. The kinds of cases that have made it to the court are generally in the realm of real-estatedeveloper architecture, everyday governmental buildings, mediocre retail spaces and fast food restaurants, what Henry-Russell Hitchcock called 'anonymous.' It is all the kind of work whose repetition is tied to tangible financial gain, and the violation of copyright is generally not claimed by architects in these cases, but by those who hire them. The high visibility projects are far and few between.

\footnotetext{
"Some of the ways that the law describes 'fair use' are perhaps the clearest way to talk about balancing originality with the disciplinary archive. 'Fair use' doctrine allows for commentary, parody, in a sense transformative use of previous work to be understood as original."
} 
FG: The recurrent use of specific elements allowed to identify 'styles': is there anything that would fall into such category, today?

AM: Style sounds so much more serious and codified than the trends we see these days. But I do think that there are a few fast morphing camps, so fleeting in a way that it may be unfair to call them camps. I will list a few that have been visible from my u.s. vantage point: a camp in which some notion of platonic, idealized typology and figuration has returned (call it Fresh Old Idealism); work with a deliberate patina of history and or historically grounded methodological experimentation (call it New Archaism); still, some digitally driven otherworldliness (Old Futurism), but now produced with the ooo alibi; the high-tech never left the corporate world (also Old Futurism); and geographically scaled graphic instigations, as new forms of activism (filed under New Futurism). And then, everything in-between these is also represented in the contemporary as well: all options have been 'checked' simultaneously. 

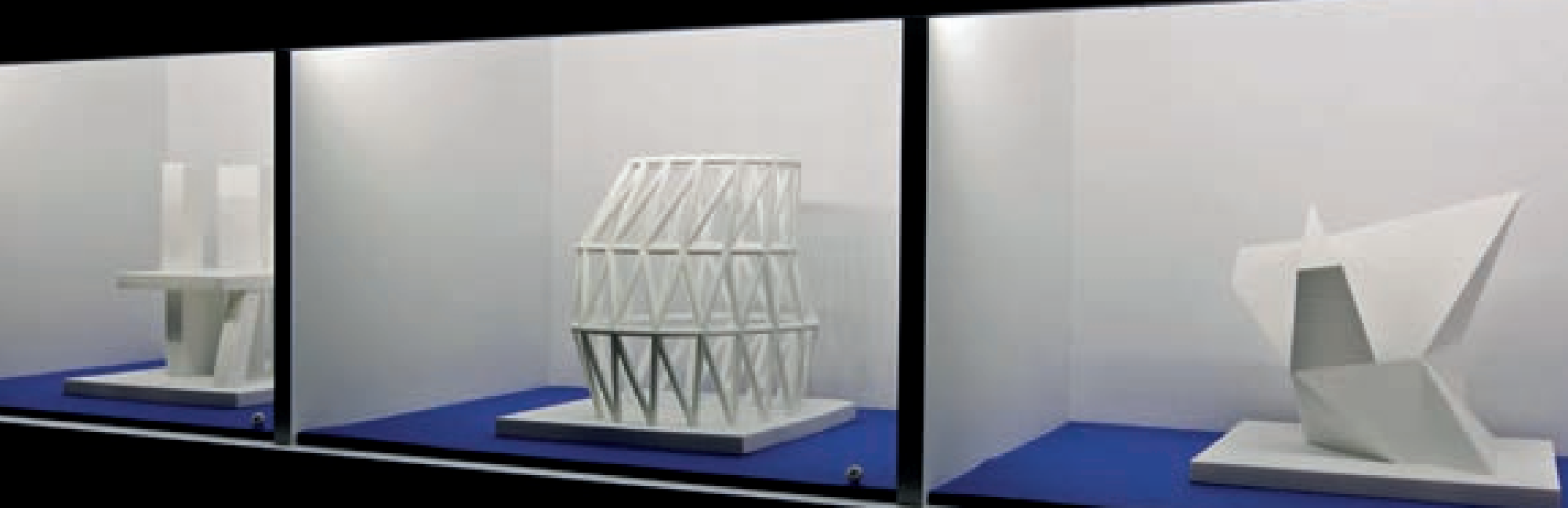

FG: How has the knowledge that you have accumulated since the beginning of this research influenced your work as an architect and as a professor?

AM: I personally operate upon the field through exhibitions, so Un/Fair Use, as well as Project_ Rorschach have been my ways of intervening in architecture culture. The U.S. pavilion at the $14^{\text {th }}$ Venice Biennale, OfficeUS, which I curated together with Eva Franch and Ashley Schafer, also explicitly asked the 'office' on the ground to intervene in dialogue with the historical issues we identified, over the span of the last century of
Exposición /

Exhibition Un/Fair Use, Berkeley

(c) Dane Pollock

"I believe that it is our collective awareness of our indebtedness to the disciplinary knowledge that safeguards architecture from endless litigation." 
U.S. architectural production abroad. As a teacher of architecture, I first tried to both embrace and problematize the issue of our collective habits of absorbing architectural images, and all images, with my Ferry Slip Mashup studio in 2009. In it we tried to script individual methodologies for producing and accessing archives, such that they could address the basic requirements of the studio program (an operating pier and ferry terminal in Portland, ME) as well as the individual design sensibilities and interests of each student. But more recently, over the last five years or so, we have been trying to embed assignments in our Core 2 studios at MIT that allow some room for students to understand historical and political baggage constitutive of certain lineages and solutions in architecture. We ask for forms of re-enactment, and inevitably, transformation of explicitly authored bodies of work in hopes that some of this kind of work and thinking with architectural history becomes part of students' embodied knowledge, problematizing all future lifting of images, as well as contemporary understanding of architecture as primarily image. ARQ 


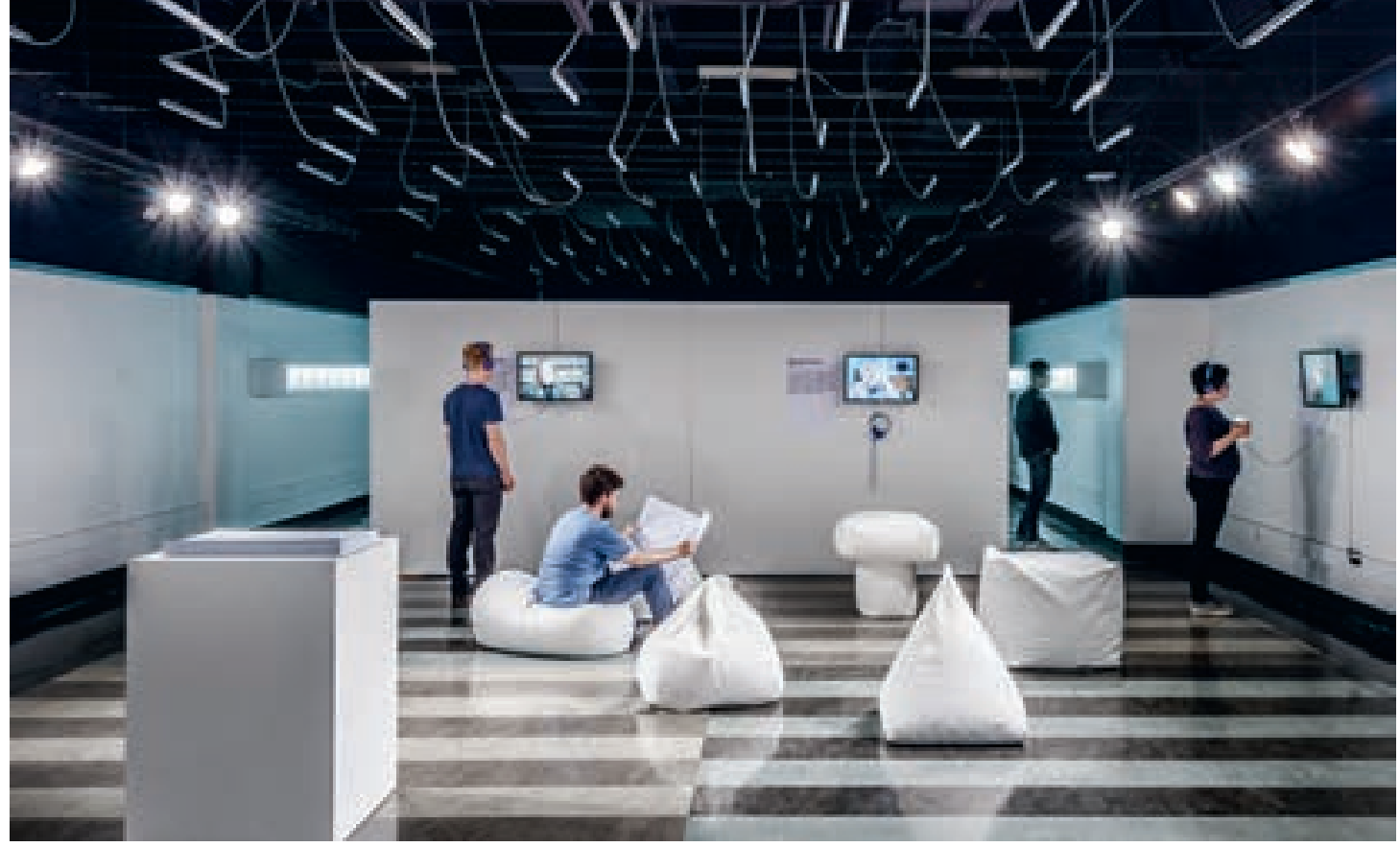

\section{UN/FAIR USE}

Curatoría y diseño / Curated and designed by:

Ana Miljački, Sarah Hirschman

Entrevistas AWCPA / AWCPA Interviews:

Sarah Hirschman

Investigación y producción / Research and Production:

Tyler Swingle, Kyle Coburn, Kyle Barker

Diseño gráfico / Graphic Design: Kyle Barker

Fotografías / Photographs: George Lin and Dane Pollock.
El equipo para la investigación y exposición Fair Use project en el MIT fueron los miembros del taller de investigación de posgrado "Appropriation: The Work of Architecture in the Age of Copyright" / Research and Exhibition Team for the Fair Use project at MIT were the members of the graduate research workshop "Appropriation: The Work of Architecture in the Age of Copyright": Kyle Barker, Christianna Bonin, Kyle Coburn, Daniela Covarrubias, Erioseto Hendranata, Juan Jofré, Alexander Marshall, Nicholas Polansky, Kelly Presutti, Kamyar Rahimi, Mikaila Waters, Travis Williams

\section{Ana Miljački}

miljacki@mit.edu

\section{Fabrizio Gallanti}

fabrizio.gallanti@mcgill.ca
Exposición / Exhibition Un/Fair Use (C) George Lin
Architect, critic and curator. M.Arch., Rice University, USA. Ph.D., Harvard University, USA, 2007. She has taught at Columbia University GSAPP, City College in New York and Harvard University GSD. Her research interests range from the role of architecture and architects in the Cold War era Eastern Europe, through the theories of postmodernism in late socialism to politics of contemporary architectural production. Miljački curated - along with Eva Franch and Ashley Schafer - the U.S. Pavilion at the 2014 Venice Architecture Biennale, called OfficeUS. Her latest exhibition, Un/Fair Use, cocurated with Sarah Hirschman was on the view at the Center for Architecture in New York from September 2015 through January 2016. Miljački is Associate Professor of Architecture at Massachusetts Institute of Technology.
Italian architect and critic based in Montreal, Canada. $\mathrm{He}$ is professor at the School of Architecture of McGill University. In 2003, along with Francisca Insulza, he founded the experimental studio FIG Projects, which explores the boundaries between architecture, urban research and visual arts. FIG Projects curated the exhibition The world in our eyes at the 2016 Lisbon Architecture Triennial . Gallanti is currently researching on the relationship between economic growth, urban development and architectural production in Latin America, with the help of fellowships by the Mellon Foundation and the Graham Foundation. 